\title{
Development and validation of the humanitarian aid workers resilience scale (HAWRS)
}

\author{
Hasan Ghodsi ${ }^{1,2}$, Sanaz Sohrabizadeh*3, Reza Khani Jazani ${ }^{4,2}$, Amir Kavousi ${ }^{5,6}$ \\ Received: 31 Dec 2018 \\ Published: 28 Dec 2019
}

\section{Abstract}

Background: Humanitarian aid workers experience various challenges in disasters, which affects their wellbeing. Being resilience can help volunteers to adapt to them. This study was conducted to develop and validate a resiliency questionnaire to evaluate the resilience of humanitarian aid workers in disasters.

Methods: This study was conducted in 2 phases between Dec 2017 and Oct 2018. In the first phase for item generation, we used qualitative content analysis. Face-to-face semi-structured interviews with 18 humanitarian aid workers were used for data collection. In the second phase, by conducting a quantitative study, the psychometric properties of the scale including face, content and construct validities as well as internal and external reliabilities, were determined. Data analysis was performed using SPSS 19 and the significance level was set at less than 0.05 .

Results: Six main subjects were extracted from the first-stage data using content analysis. The final questionnaire included six factors and 31 items after validity and reliability criteria analysis. These six factors including organizational supports, individual factors, organizational planning, social support, teamwork and challenges of disaster scene included $52.19 \%$ of the variance. The internal consistency was confirmed as well (Cronbach's alpha $=0.814$ ).

Conclusion: This specific self-assessment questionnaire can be used for scoring the resilience of humanitarian aid workers in disasters. In the case of low resilience score of volunteers, managers should avoid sending them on missions and try to improve their resilience through educational programs.

Keywords: Humanitarian aid workers, Resilience scale, Disaster

Conflicts of Interest: None declared

Funding: Shahid Beheshti University of Medical Sciences, Tehran, Iran

*This work has been published under CC BY-NC-SA 1.0 license.

Copyright $\odot$ Iran University of Medical Sciences

Cite this article as: Ghodsi H, Sohrabizadeh S, Khani Jazani R, Kavousi A. Development and validation of the humanitarian aid workers resilience scale (HAWRS). Med J Islam Repub Iran. 2019 (28 Dec);33:155. https://doi.org/10.47176/mjiri.33.155

\section{Introduction}

Every year, thousands of volunteers are sent to work in natural or man-made disasters. The purpose of their actions is to provide essential support for the affected population and alleviate their suffering $(1,2)$. However, during the mission, volunteers may face dangerous and intricate situations that often have not been adequately prepared for them. Some of these factors experienced by them are exposure to death, injury, grief, unsafety (3), burnout (4), sleep problems, anxiety, depression and posttraumatic

Corresponding author: Dr Sanaz Sohrabizadeh, sohrabizadeh@sbmu.ac.ir

1. Department of Nursing \& Midwifery, Neyshabur University of Medical Sciences, Neyshabur, Iran

2. Department of Health in Disasters and Emergencies, School of Public Health and Safety, Shahid Beheshti University of Medical Sciences, Tehran, Iran

3. Safety Promotion and Injury Prevention research center, School of Public Health and Safety, Shahid Beheshti University of Medical Sciences, Tehran, Iran

4. Men's Health and Reproductive Health Research Center, Shahid Beheshti University of Medical Sciences, Tehran Iran

5. Workplace Health Promotion Research Center, Shahid Beheshti University of Medical Sciences, Tehran, Iran

6. Department of Epidemiology, School of Public Health and Safety, Shahid Beheshti University of Medical Sciences, Tehran, Iran stress disorder (PTSD) (5-7).

Some studies have indicated that the prevalence range of PTSD in disaster relief workers varies from $6.2 \%$ to $42 \%(8)$, and depression rates range from $4 \%$ to $68 \%(9$, $10)$, and these can increase the risk of occupational burnout among them.

Such distress affects not only volunteer's mental health, but also affect the productivity and functioning of their organizations (8). Many of them have had little experi-

\section{$\uparrow$ What is "already known" in this topic:}

Resilience is a key factor for humanitarian aid workers. The lack of a specific scale to assess resilience in humanitarian aid workers is highlighted.

\section{$\rightarrow$ What this article adds:}

Humanitarian aid workers' resilience scale (HAWRS) which has been developed and validated in this study, can be used specifically to assess the resilience of humanitarian aid workers in disasters. 
ence, training, or preparation in disaster response. They often work for a few days and then have no contact with their agency and do not receive any support; thus, they may be more vulnerable to mental health problems.

Resilience is a key factor that can decrease burnout in professional personnel and have a protective role (11). In other words, resilience can help people to adapt to their challenges (12). Many factors affect volunteer's resilience. Recognizing these factors is important and useful for organizations that deploy volunteers (2). Although there are some studies on resiliency of humanitarian aid workers, the lack of specific questionnaire for assessing the resilience of humanitarian aid workers highlights the need for developing a valid scale for volunteers (13).

The aim of the present study was to develop a resilience scale of Iranian humanitarian aid workers and its validity, which is compatible with the Iranian context (Appendix 1). This questionnaire can help managers to identify volunteers who have low resiliency. Such identification can prevent the challenges of sending them to missions.

\section{Methods}

\section{Study Design and Setting}

This study which was conducted between Dec 2017 and Oct 2018 in Iran includes extracting the subjects of the resilience of humanitarian aid workers, and validity and reliability criteria analysis. Content analysis and data generation were carried out in the first phase. Psychometric properties of the tool and its validity and reliability were conducted at the second phase. This study was conducted on volunteers who worked in the Iranian humanitarian organizations in Iran (14).

\section{Designing the Humanitarian aid workers resilience scale}

In the first phase, fieldwork was performed. a number of 18 humanitarian aid workers (from different organizations) with experience of humanitarian operations were selected by purposive sampling method. Data were gathered using semi-structured face to face interviews to explore the resilience factors. All interviews were held in Persian, then transcribed verbatim and translated into English. Some examples of the questions used for the interview included "Talk about your experience of volunteering in disasters", "Talk about your problems during humanitarian missions" and "Talk about your strategies for solving these problems". Data collection was continued until data saturation was achieved. Graneheim's approach was used for data analysis (15).

In the second phase, the item pool was generated based on a literature review and finding of the first phase. The psychometric properties of HAWRS including face, content and construct validities as well as reliability, were evaluated.

\section{Trustworthiness}

In this study to increase credibility, we engaged in close interaction with participants from various settings, selected the best meaning units and categories, and drew on the best quotations from interviews. Member check and ex- ternal check were used to increase dependability. All documentation kept by researchers in this study to increase conformability. To increase transferability, we used purposive sampling, and participants were selected from a various setting (16).

\section{Psychometric evaluation}

Face validity: Qualitative and quantitative face validity was done. To assess qualitative face validity, 10 volunteers who worked in humanitarian aid organizations were invited to read the items, comment on the relevance, and difficulty of each item. Then items were revised and rewritten based on their views. To evaluate quantitative face validity, 10 volunteers were asked to rate the importance of the items on five-point Liker scale. The item impact $\geq 1.5$ indicated the appropriateness of the item (17).

Content validity: Content validity ratio (CVR) and content validity index (CVI) during this step were done. A number of 10 experts in disaster management and instrument development was asked to score each item on a three-point scale ('necessary', 'useful but not necessary', and 'unnecessary') for calculating the CVR. Then items with CVR values of 0.62 or higher were selected, based on the Lawshe Table (18).

To calculate the CVI, 10 experts were invited to rate the relevance of each item. To calculate the item-level content validity index (I-CVI), the number of experts who scored a particular item as 3 or 4 was divided by the total number of experts. A CVI value of 0.79 or higher was considered satisfactory (19).

To calculate the scale -level content validity index (SCVI), the S-CVI average (S-CVI/Ave) technique was used, and a S-CVI/Ave value greater than 0.90 indicated a very good content validity (19).

Construct validity: Exploratory factor analysis (EFA) was used to investigate the factor structure of the tool. In this process, the number of variables based on similarities between them is reduced to a smaller number of factors. Kaiser-Meyer-Olkin (KMO) test for Sampling Adequacy was done at the beginning of EFA.

Sample size: The sample size was considered at least 150-300 cases or 5-10 individuals per item in the Scale $(20,21)$. The participants were selected by random cluster sampling from Iranian Humanitarian aid workers who were active in different cities and organizations. Lack of serious mental and physical illness and having at least one experience in the disaster were considered as inclusion criteria. People who had not completed the scale were excluded. The scale has two parts: 1- demographic characteristic (age, sex, educational level, organization, and marital status and experience years), 2- Humanitarian aid workers resiliency items.

Reliability: The internal consistency of the scale was examined by Cronbach's alpha and stability of the scale was examined using the test-retest method (22). To measure the stability of scale using the intraclass correlation coefficient (ICC), a sample of Humanitarian aid workers $(n=30)$ completed the HAWRS twice with a 14 days interval.

Statistical analysis: In order to be sure of sample ade- 
quacy, the Kaiser-Meier-Olkin test was performed. For assessing construct validity, varimax rotation was used and for factor extraction, the Maximum Likelihood Estimation (ML) was applied. In the extracted factors, minimum factor loading 0.40 was used to keep the items. To measure the number of HAWRS factors, a scree plot with eigenvalues higher than 1 was used (23). SPSS 19 software was used for data analysis.

\section{Results}

At the end of the qualitative study, a pool of 142 items was extracted. Items that had overlap with others were excluded. Finally, 61 items remained for psychometric assessment at the next stage.

A total of 220 questionnaires was collected. After excluding a number of 20 incomplete questionnaires (9\%), 200 questionnaires were analyzed (response rate 91\%).
The participants were mostly male $(72 \%)$. The mean age of participants varied from 18 to 58 years (mean = $31.52 \pm 7.52$ years), and their experience in humanitarian aid works ranged from 1 to 35 years (mean $=7.32 \pm 4.48$ years) respectively (Table 1 ).

In the face validity assessment, no items were omitted because the impact factor score was above 1.5. In the CVR assessment, 7 items were removed because $\mathrm{p}<0.6$ and in the CVI assessment, 2 items were omitted. Total CVI score was 0.94 . At the end of this stage, a number of 52 items remained in the scale.

Then an explanatory factor analysis (EFA) was performed to identify the factorial structure of the Humanitarian aid workers' resiliency scale with 52 items. At this phase, a KMO test and Bartlett's test of sphericity were performed, finding a KMO value of 0.733 indicated that sample size was appropriate for factor analysis, the result

\begin{tabular}{|c|c|c|}
\hline Variable & Status & Frequency $(\%)$ \\
\hline \multirow[t]{2}{*}{ Marital status } & Single & $72(36 \%)$ \\
\hline & Married & $128(64 \%)$ \\
\hline \multirow{3}{*}{ Educational Degree } & Under diploma & $61(30.5 \%)$ \\
\hline & Bachelors & $101(50.5 \%)$ \\
\hline & Masters and higher & $38(19 \%)$ \\
\hline \multirow{3}{*}{ Work Experience (year) } & $1-5$ years & $75(37.5 \%)$ \\
\hline & $6-10$ years & $110(55 \%)$ \\
\hline & $>10$ years & $15(7.5 \%)$ \\
\hline
\end{tabular}

Table 2. Rotated Factor Loadings for the 31-Item Instrument

\begin{tabular}{|c|c|c|c|c|c|}
\hline \multirow[t]{2}{*}{ Factors and themes } & \multicolumn{5}{|c|}{ Rotated component matrix } \\
\hline & 12 & 3 & 4 & 5 & 6 \\
\hline \multicolumn{6}{|l|}{ Organizational Support } \\
\hline The experiences of the volunteers are important to the authorities of the organization & 0.615 & & & & \\
\hline Creating motivation (competitions, trips...) is a part of the authorities plans & 0.748 & & & & \\
\hline Psychological support (before, during and after missions) will be presented to volunteers & 0.802 & & & & \\
\hline Up-to-date facilities and equipment will be available for the volunteers & 0.703 & & & & \\
\hline The organization provides complete information of the mission to volunteers & 0.457 & & & & \\
\hline \multicolumn{6}{|l|}{ Individual Factors } \\
\hline I believe in my personal capabilities & 0.55 & & & & \\
\hline I have received the necessary education for dealing with stress in disasters scene & 0.474 & & & & \\
\hline I like teamwork & 0.533 & & & & \\
\hline I can communicate well with team members & 0.412 & & & & \\
\hline I forget bad memories of the mission using the methods I have learned & 0.588 & & & & \\
\hline I use relaxation techniques to reduce stress & 0.472 & & & & \\
\hline I am consulting with others in the face of stress & 0.572 & & & & \\
\hline In the face of problems in the disaster scene, prayer gives me relief & 0.548 & & & & \\
\hline \multicolumn{6}{|l|}{ Organizational Planning } \\
\hline The organization chooses competent individuals as leaders in the missions & & 0.586 & & & \\
\hline The organization has plans to deal with the crisis & & 0.719 & & & \\
\hline The organization provides food and facilities for volunteers at the missions & & 0.702 & & & \\
\hline Reinforcements arrive on time in missions & & 0.635 & & & \\
\hline The organization has plans for preparing volunteers before the mission & & 0.613 & & & \\
\hline Professional training will be performed for the volunteers & & 0.511 & & & \\
\hline \multicolumn{6}{|l|}{ Social Support } \\
\hline My family agrees with my presence in the missions & & & 0.598 & & \\
\hline My family supports me when I'm on missions & & & 0.601 & & \\
\hline Communicating with my family while on missions gives me positive energy & & & 0.512 & & \\
\hline The media supports volunteers activities & & & 0.558 & & \\
\hline The people appreciate the volunteers & & & 0.544 & & \\
\hline \multicolumn{6}{|l|}{ Team Work } \\
\hline The volunteers support each other & & & & 0.800 & \\
\hline The volunteers have friendly relationships together in missions & & & & 0.785 & \\
\hline Teamwork is being done on mission & & & & 0.722 & \\
\hline \multicolumn{6}{|l|}{ Challenges of Disaster Scene } \\
\hline Crowds have a negative impact on my performance & & & & & 0.777 \\
\hline Insecurity at the scene of disaster prevents doing my job & & & & & 0.752 \\
\hline The stress of encountering disaster scene has a negative impact on my performance & & & & & 0.768 \\
\hline At the scene of the disaster, bad behaviors of the injured person, disappoint me & & & & & 0.651 \\
\hline
\end{tabular}


Table 3. Cronbach's alpha values of six factors

\begin{tabular}{lccc}
\hline Factors & Cronbach's alpha & Number of items & $\mathrm{p}$ \\
\hline Organizational Support & 0.860 & 5 & $<0.001$ \\
Individual Factors & 0.779 & 8 & $<0.001$ \\
Organizational Planning & 0.812 & 6 & $<0.001$ \\
Social Support & 0.794 & 5 & $<0.001$ \\
Team Work & 0.811 & 3 & $<0.001$ \\
Challenges of disaster scene & 0.830 & 4 & $<0.001$ \\
\hline
\end{tabular}

of the sphericity test indicated the scale's ability to categorize the items and form factors $(\mathrm{p}<0.001)$.

Varimax rotation showed that $52.199 \%$ of the total variance was related to six factors (Table 2).

Factor one contained 5 items related to organizational support. Factor two included 8 items related to individual factors. Factor three contained 6 items related to organizational planning. Factor four included 5 items related to social supports. Factor five contained 3 items related to teamwork. Factor six consisted of 3 items related to the challenges of the disaster scene.

The ICC of the HAWRS was 0.865 , and the ICC of its dimensions ranged from 0.77 to 0.86 , confirming the stability of the scale (24) which indicated the good stability of the HAWRS. The internal consistency of the scale was calculated using the Cronbach's alpha coefficient of 0.814 , which indicated the good homogeneity of the HAWRS items (Table 3).

\section{Discussion}

According to validity and reliability criteria, the 31 -item instrument is applicable to assess the resilience of Humanitarian aid workers in disasters.

Despite the importance of the issue of resiliency for the volunteers, the literature showed that there has been no scale to assess resilience in Humanitarian aid workers in disasters. The KMO value was evaluated as "good" in this study that confirmed the construct validity of the questionnaire and the high quality of the factor analysis. The Cronbach's alpha showed a good value, i.e. 0.814 which is consistent with some studies $(25,26)$.

In the next section, we will discuss six factors affecting the resilience of Humanitarian aid workers:

Organizational support was the first factor that is related to resilience and reported by previous studies and contained 5 items (1).

The volunteers who receive good support from their organization, have more motivation and positive attitude in work. Organizational support has different aspects such as logistic, educational, spiritual, psychological and legal support. Volunteers who work in the humanitarian field need enough motivation to do their job well, so organizational support can help them and increase their motivation. Humanitarian organizations should support volunteers in various ways such as providing adequate safety and security, equipment in order to enhance their resiliency and achieve better outcomes in the missions (27).

Individual factor was the second subject in this scale, which contained 8 items. Physical, mental, spiritual health and knowledge, experience and motivation can improve the performance of volunteers $(26,28)$. Furthermore, having management skills and professional competencies are especially important for humanitarian aid workers. These results are consistent with the finding of a number of studies (29). Bjerneld also concluded that professional competency had an important role in the resiliency of volunteers (30). Spirituality and religion can help people to adapt with stress in a disaster scene. Thus, trust in God as well as focusing on spirituality are very effective strategies of stress management and increase of resiliency at the time of disasters (31).

The third factor was organizational planning, which included 6 items and reported by previous studies (27). Bjerneld concluded that ineffective planning and support could increase the likelihood of depression (30). Selection of competent leaders who have management and leadership skills in missions, providing proper education and training for volunteers and implementing specific leadership training have important effects on the resilience of personnel (32). Replacing personnel before exhaustion is an important issue in organizational planning, which can enhance the resilience of humanitarian aid workers (2).

Social support was the fourth factor in this scale which contained 5 items. Social support has various aspects such as family, community, media, and team member's supports. This factor is an essential category of resilience that has a positive correlation with the mental state of personnel (33). Ebadi concluded that social support could improve the resilience of EMS personnel (26). Supports received from family, society or media can increase the selfesteem of personnel and improve their performance (34). Cardozo concluded that lower levels of psychological distress, depression and burnout were significantly associated with social supports. (8).

The fifth factor in this scale was teamwork which contained 3 items. Team work has a positive effect on organizational and individual outcomes. A low level of resiliency can be related to insufficient intra-team connection (35). Leader and members of teams should learn effective strategies to support their peers. Accordingly, other studies suggested that teamwork, as well as strong sense of community, can be major protective factors for disaster workers, and they should have good communication with other team members (36).

The sixth factor was the challenges of the disaster scene, which contained 4 items. Different challenges in disasters can increase the stress of aid workers and decrease their resilience (3). Thus, humanitarian organizations need to identify these factors and reduce them to improve the motivation of aid workers. These findings are consistent with the finding of the Froutan study which reported jobrelated stress factors in EMS (31).

The questionnaire was developed for the Iranian context and thus, it may be generalized to some similar contexts. In addition, we did not implement confirmatory factors 
analysis to determine the cut-off points

\section{Conclusion}

The results showed that the Humanitarian aid worker resilience scale (HAWRS) has suitable psychometric properties. This specific self-report questionnaire can be used by managers and organizations for assessing the resiliency of their volunteers. Accordingly, it is highly suggested that volunteers with low resilience levels should be avoided to dispatch to any mission by humanitarian organization managers to prevent any negative effect. The educational program is advised to improve the resiliency of volunteers who suffer from the low levels of resiliency at the disaster scene.

\section{Ethical statement}

This study was approved and affirmed by the Ethics Committee of the Shahid Beheshti University of Medical Sciences (IR.SBMU.RETECH.REC.1396.208), Tehran, Iran. Participants were personally informed regarding the objectives of the study, anonymity of their information, and their ability to either participate in or withdraw from the study.

\section{Acknowledgments}

We are grateful to Shahid Beheshti University of Medical Sciences, for financial support. Also, the authors would like to express their gratitude to all the personnel who participated in this study.

\section{Conflict of Interests}

The authors declare that they have no competing interests.

\section{References}

1. Blanchetière, P. Resilience of Humanitarian Workers. MSc Dissertation, Manchester, UK; 2006.

2. Brooks SK, Dunn R, Sage CAM, Amlôt R, Greenberg N, Rubin GJ. Risk and resilience factors affecting the psychological wellbeing of individuals deployed in humanitarian relief roles after a disaster. J Ment Health. 2015;24(6):385-413.

3. Stamm BH, Higson-Smith C, Hudnall AC. The complexities of working with terror. In D. Knafo (Ed.), Living with terror, working with trauma: A clinician handbook. 2004:369-395. Northvale, NJ: Jason Aronson.

4. Parker CL, Noll C, Everly GS. Self-care and care for the caregiver. In G. S. Everly \& C. L. Parker (Eds.), Mental health aspects of disaster: Public health preparedness and response. Baltimore, MD: Johns Hopkins Center for Public Health Preparedness; 2005.

5. Benedek DM, Fullerton C, Ursano RJ. First responders: Mental health consequences of natural and human-made disasters for public health and public safety workers. Ann Rev Public Health. 2007;28:55-68.

6. Fullerton CS, Ursano RJ, Wang L. Acute stress disorder, posttraumatic stress disorder, and depression in disaster or rescue workers. Am J Psychiatry. 2004;161(8):1370-1376.

7. Kleim B, Westphal M. Mental health in first responders: A review and recommendation for prevention and intervention strategies. Traumatology. 2011;17(4):17.

8. Lopes Cardozo B, Gotway Crawford C, Eriksson C, Zhu J, Sabin M, Ager A, et al. Psychological Distress, Depression, Anxiety, and Burnout among International Humanitarian Aid Workers: A Longitudinal Study. PLoS One. 2012;7(9):e44948.

9. Thormar SB, Gersons BPR, Juen B, Djakababa MN, Karlsson T, Olff M. Organizational factors and mental health in community volunteers:
The role of exposure, preparation, training, tasks assigned, and support. Anxiety Stress Coping. 2013;26(6):624-642.

10. Ager A, Pasha E, Yu G, Duke T, Eriksson C, Cardozo BL. Stress, mental health, and burnout in national humanitarian aid workers in Gulu, Northern Uganda. J Trauma Stress. 2012;25:713-720.

11. Shojafard J, Poursadegh N, Shahr Ashoub G, Zangisheh S. Relationship between Burnout and Resilience in Emergency Medicine Personnel in Tehran. J Rescue Relief. 2014;6(2).

12. Jackson D, Firtko A, Edenborough M. Personal resilience as a strategy for surviving and thriving in the face of workplace adversity: a literature review. J Adv Nurs. 2007;60(1):1-9.

13. Ghodsi H, Khani Jazani R, Sohrabizadeh S, Kavousi A. The Resiliency of Humanitarian Aid Workers in Disasters: A Qualitative Study in the Iranian Context. Iran Red Crescent Med J. 2019 February;21(2):e80366.

14. "IRCS among top five int'l relief bodies". Iran daily. 4 January 2015.

15. Graneheim UH, Lundman B. Qualitative content analysis in nursing research: concepts, procedures and measures to achieve trustworthiness. Nurse education today. 2004; 24(2):105-12.

16. Guba EG, Lincoln YS. Effective Evaluation: Improving the Usefulness of Evaluation Results through Responsive and Naturalistic Approaches. San Francisco: Jossey- Bass; 1981.

17. Broder HL, McGrath C, Cisneros GJ. Scale development: face validity and item impact testing of the Child Oral Health Impact Profile. Commun Dent Oral Epidemiol 2007;35(Suppl 1):8-19.

18. Lawshe CH. A quantitative approach to content validity1. Pers Psychol 1975; 28(4):563-75.

19. Polit DF, Beck CT, Owen SV. Is the CVI an acceptable indicator of content validity? Appraisal and recommendations. Res Nurs Health 2007;30(4):459-67.

20. Hutcheson G, Sofroniou N. The Multivariate Social Scientist: Introductory Statistics Using Generalized Linear Models. Thousand Oaks, CA: Sage Publication; 1999.

21. Plichta Kellar S, Kelvin E. Munro's Statistical Methods for Health Care Research. Sixth Ed. ed: Lippincott Williams and Wilkins. Wolters Kluwer Health; 2012.

22. Grove SK. The practice of nursing research: appraisal, synthesis, and generation of evidence. Nurs Stand. 2013;27(31):30.

23. Williams B, Onsman A, Brown T. Exploratory factor analysis: a five-step guide for novices. Aus J Paramed. 2014;8(3).

24. Terwee CB, Bot SD, de Boer MR, van der Windt DA, Knol DL, Dekker J, et al. Quality criteria were proposed for measurement properties of health status scales. J Clin Epidemiol. 2007;60(1):34-42.

25. Connor KM, Davidson JRT. Development of a new resilience scale: the Connor- Davidson resilience scale (CD-RISC). Depress Anxiety. 2003;18(2):76-82.

26. Ebadi A, Froutan R, Malekzadeh J. The design and psychometric evaluation of the emergency medical services resilience scale (EMSRS). Int Emerg Nurs. 2019;42:12-18.

27. Quevillon RP, Gray BL, Erickson SE, Gonzalez ED, Jacobs GA. Helping the Helpers: Assisting Staff and Volunteer Workers Before, During, and After Disaster Relief Operations. J Clin Psychol. 2016;72(12):1348-63.

28. Habibipour B, Vanaki Z, Hadjizadeh E. The effect of implementing "Goal Setting Theory" by nurse managers on staff nurses' job motivation. Iran J Nurs. 2009;22(57):67-76.

29. Lisa M. Building Resilient Managers in Humanitarian Organizations: Strengthening Key Organizational Structures and Personal Skills that Promote Resilience in Challenging Environments. People in Aid. 31 Dec 2011.

30. Bjerneld M, Lindmark G, McSpadden LA, Garrett MJ. Motivations, concerns, and expectations of Scandinavian health professionals volunteering for humanitarian assignments. Disaster Manage Response. 2006;4(2):49-58

31. Froutan R, Khankeh HR, Fallahi M, Ahmadi F, Norouzi K. Resiliency Improvements in medical emergency staff in burn missions: a qualitative study in an Iranian context. Iran Red Crescent Med J. 2015;17(7):e22495.

32. Walsh DS. Interventions to reduce psychosocial disturbance following humanitarian relief efforts involving natural disasters: an integrative review. Int J Nurs Pract. 2009;15(4):231-40.

33. Park KO. Social support for stress prevention in hospital settings. J R Soc Promotion Health 2007;127(6):260-4.

34. Verhaeghe M, Bracke P, Bruynooghe K. Stigmatization and self- 
esteem of persons in recovery from mental illness: the role of peer support. Int J Soc Psychiatry. 2008;54(3):206-18.

35. Williams R, Greenberg N. Psychosocial and mental health care for the deployed staff of rescue, professional first response and aid agencies, NGOs and military organisations. In: Ryan JM, Hopperus Buma APCC, Beadling CW, et al., eds. Conflict and catastrophe medicine: A practical guide. 3rd ed. London: Springer-Verlag. 2014;395-432.

36. Antares Foundation. Managing stress in humanitarian workers: Guidelines for good practice. Amsterdam, the Netherlands: Antares Foundation. Retrieved from https://antaresfoundation. Org/File Library/file6782.pdf. 2012.

Appendix 1. Humanitarian aid workers resilience scale

\begin{tabular}{ll}
\hline Never Rarely Some times Often $\quad$ Always & \\
\hline & Crowds have negative impact on my performance \\
& Insecurity at the scene of disaster prevents doing my job \\
& Stress of encounter with disaster scene has negative impact on my performance \\
At the scene of the disaster, the bad behavior of the injured person, disappoint me & I believe in my personal capabilities \\
I have received the necessary education for dealing with stress in disasters scene \\
I like teamwork \\
I can communicate well with team members \\
I forget bad memories of the mission, with the help of the methods I have learned \\
I use relaxation techniques to reduce stress \\
I am consulting with others in the face of stress \\
In the face of problems in disaster scene, prayer gives me relief \\
The organization chooses competent individuals as leaders in the missions \\
The organization has plans to deal with the crisis \\
The organization provides food and facilities for volunteers at the missions \\
Reinforcements arrive on time in missions \\
The organization has plans for preparing volunteers before the mission \\
Professional training will be performed for the volunteers \\
The experiences of the volunteers are important to the authorities of the organization \\
Creating motivation (competitions, trips...) is a part of the authorities plans \\
Psychological support (before, during and after missions) will be presented to volunteers \\
Up-to-date facilities and equipment will be available for the volunteers \\
The organization provide Complete information of the mission to volunteers \\
The volunteers support each other \\
The volunteers have friendly relationships together in missions \\
Teamwork is being done on mission \\
My family agrees with my presence in the missions \\
My family supports me when I'm on missions \\
Communicating with my family while on missions gives me positive energy \\
The media supports volunteers activities \\
The people appreciate the volunteers \\
\hline
\end{tabular}

